\title{
6 \\ A Laboratory Rig for Testing Runoff from Paved Surfaces
}

William James, Stuart C. Wylie, and Robert C. Johanson

When a process is too complex for rigorous mathematical formulation, and simplifying assumptions are introduced for its solution, experimental verification is required, or the approximate numerical model cannot be said to represent the process. Numerical solution of the dynamic wave equations for flow over pavement is such a case. We describe in this chapter a laboratory rig used to test the numerical procedures of the previous chapter (James and Wylie, 2000), and the initial storage theory developed in the previous monograph in this series (James and Johanson, 1999). Our experiments were conducted almost 30 years ago in the Department of Civil Engineering at the University of Natal in Durban. Laboratory conditions were stringently controlled. Experiments are otherwise similar to those recently described by several of the author's graduate students in this series of books.

For generality of the mathematical model, the formulation of the wave equations should include a momentum exchange term for rain distributed uniformly over its resulting runoff from the pavement. In the present studies, the mathematical and physical model catchments are also impermeable, to avoid the complexity of infiltration. Under these conditions, the physical and mathematical models may be considered to represent real rain falling on its resultant runoff from an impervious pavement (Amorocho and Hart, 1965).

\footnotetext{
James, W., S.C. Wylie and R.C. Johanson. 2000. "A Laboratory Rig for Testing Runoff from Paved Surfaces." Journal of Water Management Modeling R206-06. doi: 10.14796/JWMM.R206-06. (c) CHI 2000 www.chijournal.org ISSN: 2292-6062 (Formerly in Applied Modeling of Urban Water Systems. ISBN: 0-9683681-3-1)
} 
For our rig, the basic requirement is a plane pavement of significant width compared with flow depth. The length and slope were chosen to produce hydrographs having steep rising limbs, to conserve experimentation time (Morgali and Linsley, 1965). Essential requirements for the rig were facilities for measuring rates of input to, and runoff from the flow surface, with sufficient accuracy that the reliability of the experimental results should not be in doubt. Such a small, laboratory catchment apparatus is relatively easy to build and can yield accurate data under a variety of precisely controlled conditions. Our rig described here is considered to display the essential attributes of a real pavement system with respect to behavior of a range of rain and overland flow or runoff.

Figure 6.1 is a view looking upstream. Occupying a floor area of about $3 \mathrm{~m}$ $\mathrm{x} 4 \mathrm{~m}$ and a height of $3 \mathrm{~m}$, it was constructed on a framework of slotted angle section steel. Nozzles were mounted on the sides of the frame and directed upwards. Runoff was collected in a container that was weighed continuously.

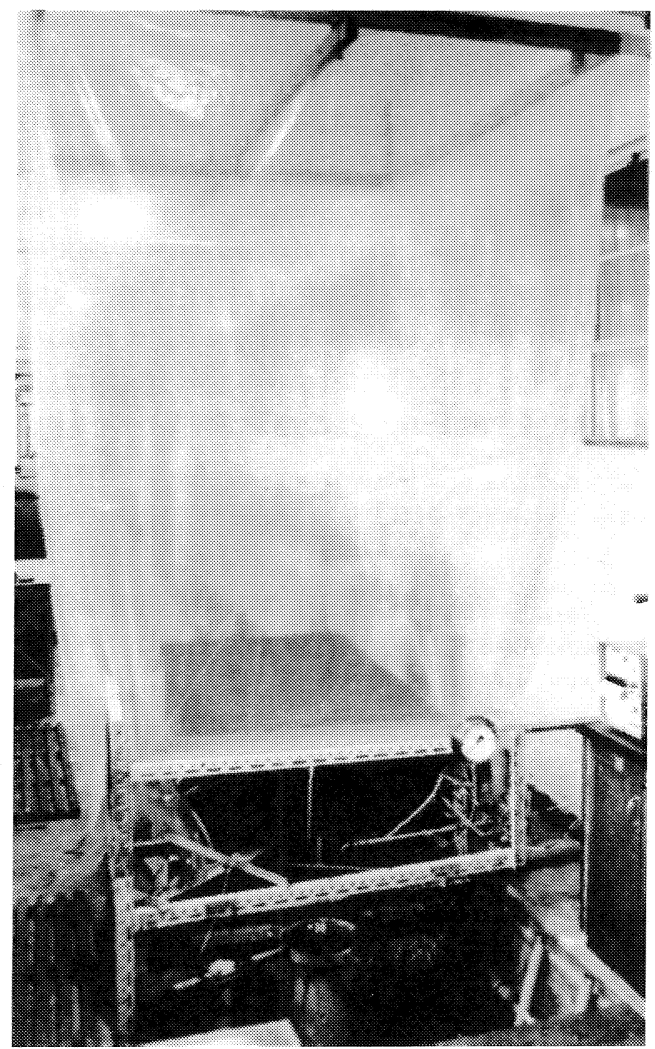

Figure 6.1 General view of the laboratory rig. 


\subsection{The Rain System}

Figure 6.2 indicates the water supply system. Water was supplied from a $50 \mathrm{~mm}$ main below the laboratory floor at approximately $600 \mathrm{kPa}$. One Norgren model $2 \mathrm{H}$ automatic pressure-regulating valve was installed, providing reduced but stabilized - almost constant - downstream pressure that could be varied between 0 and $200 \mathrm{kPa}$. Rain rates varied up to $205 \mathrm{~mm} / \mathrm{h}$.

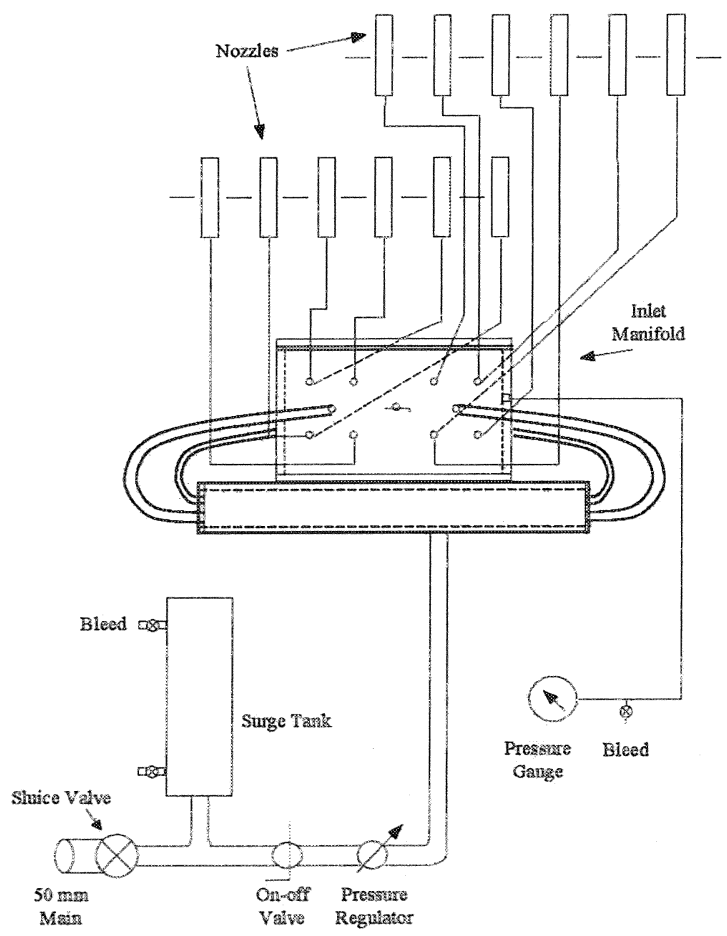

Figure 6.2 Water supply schematic.

In the supply to the regulating valve, a small surge tank was installed to prevent water hammer effects in and from the supply main. Between the surge tank and the pressure-regulating valve a lever-operated, quick-acting on-off ball valve was installed in the supply line. When the valve was opened, the nozzle discharge attained full value almost instantaneously, while the decay time after closure was approximately $0.5 \mathrm{~s}$.

Housed below the catchment surface, $300 \mathrm{~mm}$ above the laboratory floor, the connection from the pressure-regulating valve to the manifold feeder comprised a steel pipe of $15 \mathrm{~mm}$ nominal bore. The manifold feeder was a $75 \mathrm{~mm}$ diameter steel pipe $375 \mathrm{~mm}$ long, whose axis was horizontal and perpendicular 
to that of the manifold itself. From each end of the feeder two $12 \mathrm{~mm}$ plastic pressure hoses fed the manifold at four points equally spaced around its circumference and half-way along its length. Hoses were of equal length to ensure equal pressures at all four manifold inlets.

Sealed with a $10 \mathrm{~mm}$ steel cover plate at one end (to which the feeder bracket was welded), the manifold comprised a short length $(175 \mathrm{~mm})$ of a $225 \mathrm{~mm}$ diameter steel pipe. It had a nominal $4 \mathrm{~mm}$ thick brass plate, strengthened with a $10 \mathrm{~mm}$ steel cover plate, having a $100 \mathrm{~mm}$ diameter central hole cut in it, at the other end. Strain gages were attached to the outside surface of the brass plate, to record changes of strain in the plate due to changes of water pressure in the manifold.

Tappings were made at twelve points around the circumference of the manifold for feeding the nozzles through $9 \mathrm{~mm}$ plastic pressure hoses, all of which were, again, cut to equal lengths, to ensure equal pressures at all twelve nozzles. An additional tapping provided a $3 \mathrm{~mm}$ connection to a Bourdon pressure gage mounted on the front of the rig, and it permitted accurate adjustment of the pressure-regulating valve. Two bleed points were provided on the manifold, one at the top for air removal during filling, and one at the bottom to drain water and suspended particles that may have settled inside. An air bleed was also provided at the pressure gage.

From measurements of natural rainfall, Laws and Parsons (1943) found that the median drop diameter increases with the rainfall intensity. In regard to fall velocity, Laws (1941) found that in still air there is a definite minimum fall height required for water drops to gain terminal velocity. For a fall less than this limiting height, the velocity varies with height.

When choosing the nozzle type, we attempted to reproduce natural rainfall on the flow surface. A perfect artificial rainfall applicator for laboratory use should produce uniform rainfall and generally perform according to the foregoing discussion. Unfortunately, at the time of the study, a perfect applicator was not available (Woo and Brater, 1962). V.D. Young is reported to have developed the Type $F$ nozzle which produced a drop size distribution similar to that of highintensity rainfall (Wilm, 1943). Incorporating a helical insert that imparts a spiral motion to the issuing jet, this nozzle improves the areal rain distribution - it has often been used in laboratory studies of thin sheet flow. Its main fault is that its drop sizes decrease with an increase in rain intensity, because the higher water pressure reduces the probability of occurrence of larger water particles. In addition, these nozzles do not produce uniform rain (Woo and Brater, 1962).

Several tests were run with one or more nozzles in various positions on the nozzle supports, and with all twelve nozzles operating together over a range of water pressures, to determine the best position for each nozzle. Figure 6.3 shows the distribution of rain obtained from the final nozzle positions selected with all twelve nozzles discharging simultaneously. In these tests, the rain was collected 


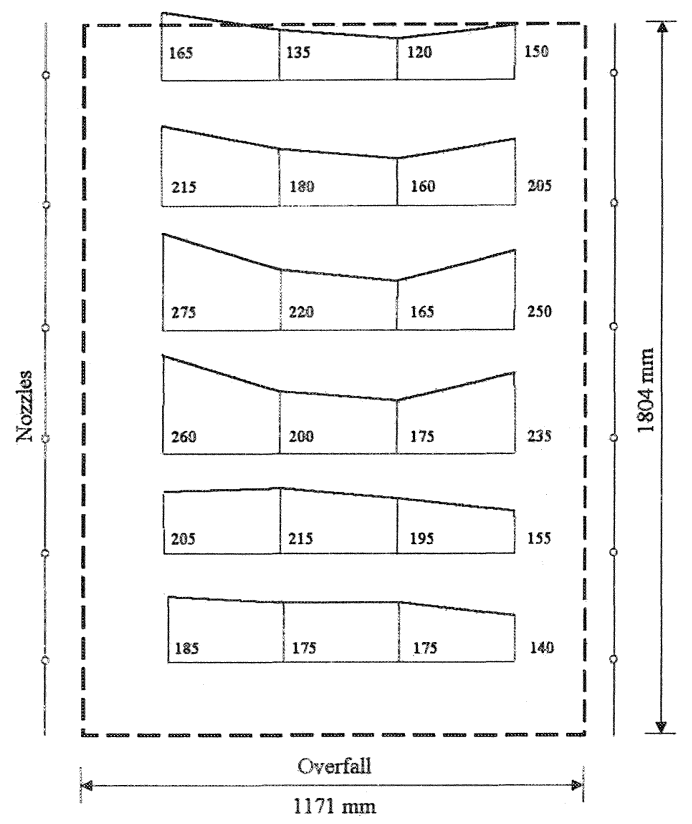

Figure 6.3 Rain distribution $380 \mathrm{~mm}$ above pavement.

Mean $=190 \mathrm{~mL} ;$ standard deviation $=40 \mathrm{~mL}$; coef of variation $=21 \% ;$ rain $=190 \mathrm{~mm} / \mathrm{h}$

in 24 off $500 \mathrm{~mL}$ measuring cylinders placed on the flow surface at equally spaced positions over its entire area. Thus the results make no allowance for splash, which tend to even out the distribution on the pavement. Maximum height above the flow surface reached by the drops from the nozzles was approximately $2 \mathrm{~m}$, from which height the water drops struck the flow surface at a velocity less than their terminal velocity.

The operating pressure limits were approximately 70 and $200 \mathrm{kPa}$. Below $70 \mathrm{kPa}$ the rain did not cover the whole flow surface and above $200 \mathrm{kPa}$, control was difficult. A further shortcoming of this nozzle was its small variation in discharge between the limits of water pressure obtainable, making the study of a wide range of flows difficult.

\subsection{The Catchment Surface}

Two fundamental rigs were used, series 1 by James and Johanson (1999) and series 2 by James and Wylie (2000). For series 1, the flow surface was rectangular and measured $1830 \mathrm{~mm} \times 1220 \mathrm{~mm}$ covered by a cloth for control of rugosity. For series 2 it measured $1804 \mathrm{~mm}$ x $1171 \mathrm{~mm}$ covered with a standard slurry-seal emulsion to reproduce flow conditions on a blacktop asphalt 
pavement. Horizontal in the shorter direction, it was tilted at a slope of $0.025 \mathrm{~m} /$ $m$ in the longer direction, and was bounded on three sides by a small knife-edged ledge to prevent loss of flow from spillage.

Flow over the surface appeared to be even, and runoff spilling over the edge was concentrated with little time lag in a large $\mathrm{V}$-shaped funnel and fell into a weighing container (Figure 6.4).

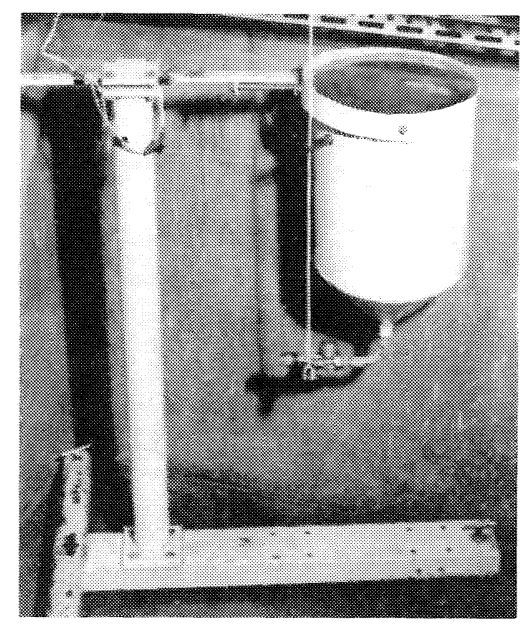

Figure 6.4 The runoff weighing bucket.

Surrounding the entire apparatus was transparent polythene sheeting suspended from a wooden framework fixed to the laboratory ceiling. Minimizing the effect of ambient air draughts on the rain, it also formed part of the drainage system for removing water that fell outside the flow surface (approximately half the total discharge from the nozzles).

\subsection{Rainfall and Runoff Measurement}

Rain rate was a function of the Bourdon gage pressure, and it was maintained constant during a test run by means of an adjusting screw on the pressureregulating valve. Start and end of rain and a measure of its intensity were recorded on a chart recorder, as described below. An accurate relationship between rain intensity and gage pressure was determined experimentally. Ranges of rain in series 1 varied between 51 and $175 \mathrm{~mm} / \mathrm{h}$, while a rain rate of about $200 \mathrm{~mm} / \mathrm{h}$ was used in series 2 .

For the determination of the outflow hydrograph, a continuous and accurate record of the rate of runoff from the flow surface is necessary. We generated and recorded an electrical signal that was proportional to the weight of runoff 
collected in a $30 \mathrm{~L}$ measuring container that was suspended freely from the end of a steel cantilever. Dimensions of the cantilever were $250 \mathrm{~mm}$ long (moment arm $430 \mathrm{~mm}$ ), $30 \mathrm{~mm}$ wide and $13 \mathrm{~mm}$ thick. Container emptying was effected through a lever-operated quick-acting on-off valve on a pipe connected to the apex of its conical bottom. Strain gages were attached to the steel cantilever, which was never loaded to its elastic limit. The relationship between known quantities of water in the container and recordings was determined experimentally, as shown in Figure 6.5, giving a maximum error in terms of an assumption of linearity of $8 \%$, near the lower boundary. Generally less than $4 \%$, it was considered satisfactory. Runoff rate was then determined from this record by numerical differentiation.

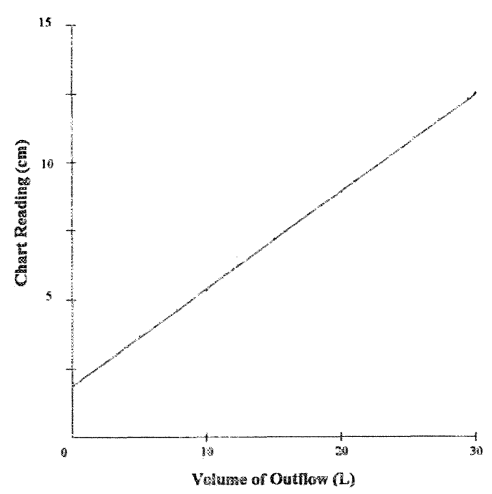

Figure 6.5 Volume calibration.

\subsubsection{Indirect Recording Systems}

These days our instrumentation is digital and collected by computer. Back then, we had to design and build our own analog instruments. Four Huggenberger strain gages ( $15 \times 10^{-4}$ maximum strain) were fixed to the outside of the brass plate sealing one end of the manifold pipe. Deflection due to the water pressure in the manifold was recorded by changes in the electrical resistance of the strain gages and used as a measure of the rain rate. Connected in a full Wheatstone bridge, the four gages formed a sensitive temperature-compensated recording system. A Hottinger-Messtechnik instrument, model KWS/T-5, provided a $5 \mathrm{kc} /$ $\mathrm{s}$ supply to the gages and also demodulated and amplified the signal due to strain. Maximum signal output was $20 \mathrm{~mA}$ with a maximum load resistance of 100 ohms. The bridge was balanced using a rheostat control.

Four Huggenberger electrical resistance strain gages were also fixed, two to the top and two to the bottom $30 \mathrm{~mm}$ faces of the steel cantilever, near its support. Also connected in a full Wheatstone bridge, the gages recorded the strain 
in the cantilever caused by its deflecting under the weight of the accumulated runoff in the measuring container. These gages also formed a sensitive temperature-compensated recording system.

An electronic circuit was designed and built by the authors as both a power supply and signal amplifier. This circuit, incorporating a Nexus SQ-10a operational amplifier, is shown in Figure 6.6. It supplied the strain gages with a constant low voltage direct current and amplified the return signal sufficiently to give a full-scale deflection on the chart recorder when the measuring container was full. The bridge could be balanced with a variable resistance when the measuring container was empty.

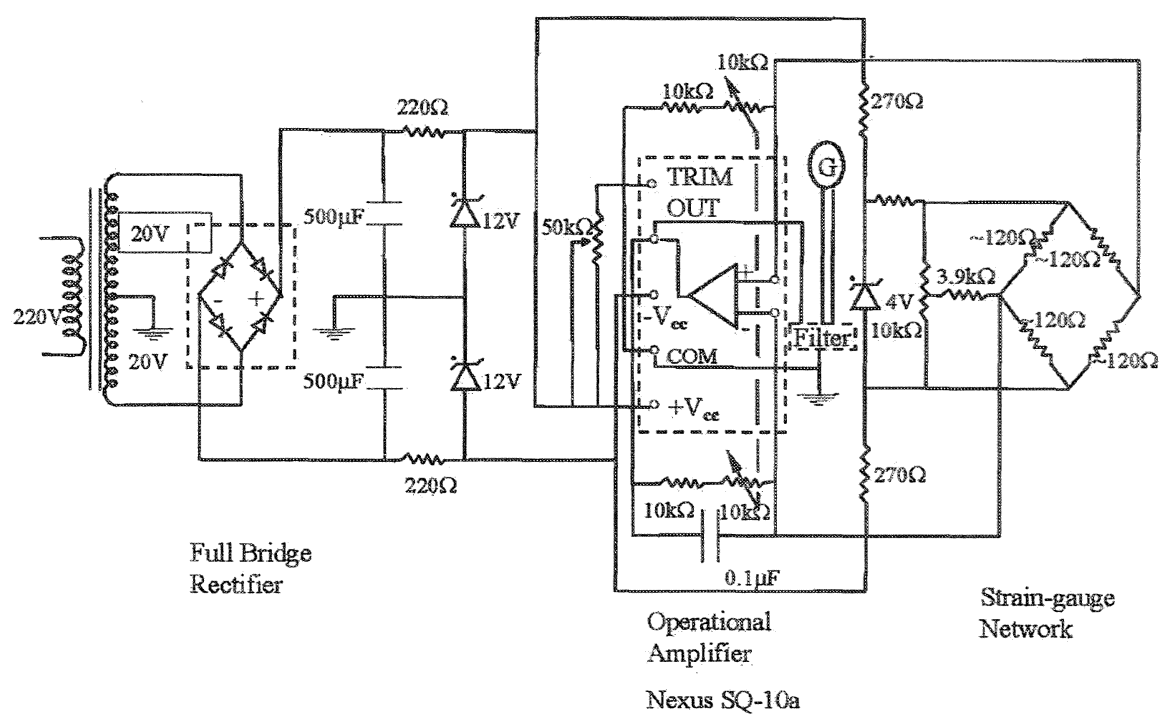

Figure 6.6 Recording circuitry.

Finally, disturbing harmonics in the alternating current signal from the input gages and oscillations in the direct current signal from the output gages were attenuated using resistance-capacitance filter networks that eliminated these disturbances while passing the desired signals. The oscillations in the output signal were reflections of the low natural-frequency vibrations of the steel cantilever, caused by the runoff falling into the measuring container. Details of the filter circuits designed and built by the authors can be provided.

An S.E. 2005 multi-channel ultra-violet recorder, manufactured by S.E. Laboratories (England) was used for recording test data. Various chart speeds could be selected and up to six input channels handled by the six sensitive mirror galvanometers incorporated in the oscillograph instrument. These were sensitive to input frequencies in the range 0 to $600 \mathrm{~Hz}$. Accurate time intervals were 
recorded simultaneously with the signals by orthogonal grid lines printed on the light-sensitive paper (Kodak Linagraph direct-print paper). This obviated errors due to paper stretch or bad grid alignment, often associated with pen recorders. Only two recorder channels were used and a chart travel of $1.25 \mathrm{~mm} / \mathrm{s}$ was found a suitable speed. Time was recorded on the chart every second.

After spilling over the edge of the flow surface, the runoff fell an average of $1020 \mathrm{~mm}$ into the measuring container. Of this, $535 \mathrm{~mm}$ was in the $\mathrm{V}$-shaped funnel, where the runoff was concentrated into a narrow stream, while the remaining $485 \mathrm{~mm}$ was free fall. Runoff therefore entered the measuring container with considerable velocity and the rate of loss of vertical momentum from this falling water caused an apparent increase in the weight of water in the container. The effect on the hydrograph (derived by differentiating the accumulated flow) was found in all cases to be less than $1 \%$ and it was therefore neglected. Detailed analysis of this phenomenon is available from the authors.

The measuring system was frequently re-calibrated using two known weights that approximated the extreme weights to be measured. A zero weight equal to that of the empty runoff container was suspended from the cantilever, the bridge balanced, and the chart reading noted. An almost full-scale-reading calibration weight was then suspended and the chart reading noted 30 seconds after placing the weights, when the system had settled down. Linear interpolation fixed the intermediate values.

\subsection{Tests and Results}

To ensure that the start-up characteristics of the catchment did not vary from one test to the next, the amount of water on the pavement was standardized as follows. Preceding every test rainfall was applied at $90 \mathrm{~mm} / \mathrm{h}$ for $30 \mathrm{~s}$. The catchment was then allowed to drain for $240 \mathrm{~s}$ before the test run was started.

In series 1, 139 documented tests were run. Typical results are shown in a chapter of the previous monograph (James and Johanson, 1999) and in the previous chapter of this monograph (James and Wylie, 2000).

\subsection{Conclusions}

The measured hydrographs exhibit the basic features normally associated with hydrographs obtained from small natural catchments. Runoff rises quickly to a peak value and rapidly recedes upon cessation of rainfall. By avoiding the problems connected with infiltration, it has been possible to obtain accurate plots of both effective rainfall and the resulting runoff. 
Any theory concerning the behavior of catchments under flood conditions should be tested over a wide range of rainfall intensities. Variation in rainfall intensity that can be produced by any rig is limited. In comparison with another rig (Amorocho and Orlob, 1961), the range of rainfall intensities used here was similar.

\section{References}

Allison, S.V. 1967 Review of Small Basin Runoff Prediction Methods. J. Hyd. Div. ASCE, 93(IRl): 1 - 6 (March).

Amorocho, J. 1963. Measures of the Linearity of Hydrologic Systems. J. Geophys. Research, A.G.U., 68(8):2237-2249(April).

Amorocho, J. and Hart W.E. 1964. A Critique of Current Methods in Hydrologic Systems Investigation. Trans. AGU, 45(2):307-321

Amorocho, J. and Hart, W.E. 1965. The use of laboratory catchments in the study of hydrologic systems. J. Hydrol., 3: 106-123

Amorocho, J., and Orlob, G.T. 1961 Nonlinear Analysis of Hydrologic Systems. Univ. of California, Water Res. Center Contribution No. 40, CA.

Grace, R.A. and Eagleson, P.S. 1965. Similarity criteria in the surface runoff process, M.I.T. Dept. Civil Eng'rg, Hydrodynamics Lab. Rept. 77.

Grace, R.A. and Eagleson, P.S. 1966. Construction \& Use of a Physical Model of the Rainfall-Runoff Process. Tech Note 11 MIT Hydrodynamic Lab.

Grace, R.A. and Eagleson, P.S. 1966 The modelling of overland flow. Water Resources Res., 2(3):393-403.

James, W. and R.C. Johanson. 1999. "A Note on an Inherent Difficulty with the Unit Hydrograph Method." Journal of Water Management Modeling R204-01. doi: 10.14796/JWMM.R204-01.

James, W. and S.C. Wylie. 2000. "Numerical Techniques for Overland Flow from Pavement." Journal of Water Management Modeling R206-05. doi: 10.14796/JWMM.R206-05.

Johanson, R.C. 1967. System analysis of the rainfall-runoff process. M.Sc.Eng. dissertation, University of Natal, Aug.

Laws, J.O. 1941. Measurements of the fall velocity of waterdrops and raindrops. Trans. Amer. Geophysical Union, 111

Laws, J.O. and Parsons, D.A. 1943.The relation of raindrop size to intensity. Trans. Amer. Geophysical Union, 11

Leendertse, J.J. Aspects of a computational model for long-period water-wave propagation RAND

Morgali, J.R. and Linsley, R.K. 1965 Computer analysis of overland flow. Proc. ASCE, J. Hyd. Div., 91(HY3):81-100, May

Wilm, H.G. 1943. The application and measurement of artificial rainfall on Type FA and F infiltrometers. Trans. Amer. Geophysical Union, 11, 480-487

Woo, D-C. and Brater, E.F. 1962. Spatially varied flow from controlled rainfall. Proc. ASCE, J. Hyd. Div, (HY6):31-56,.Nov.

Wylie, S.C. 1971. An appraisal of some numerical solutions of the dynamic wave equations. M.Sc.Eng. Dissertation, University of Natal, Aug. 